\title{
Tyrosine-Protein Kinase Receptor UFO
}

National Cancer Institute

\section{Source}

National Cancer Institute. Tyrosine-Protein Kinase Receptor UFO. NCI Thesaurus. Code C17475.

Tyrosine-protein kinase receptor UFO (894 aa, $~ 98 \mathrm{kDa}$ ) is encoded by the human AXL gene. This protein plays a role in ligand binding, signaling and cellular growth and differentiation. 